\title{
Hydrocephalus and Headaches in Paget's Disease of the Skull: Complete Relief by Ventriculo-Atrial Shunt
}

\author{
Chantal Hausser, Georges Elie Ouaknine, Jacques Sylvestre
}

SUMMARY: A 76 year old patient with a long history of headaches was found to have Paget's disease and communicating hydrocephalus. There were (otherwise) no neurological or musculo-skeletal manifestations of Paget's disease, but moderate impairment of intellectual function was present. Treatment with disphosphonates did not bring any significant improvement, but three days following a ventriculo-atrial shunting procedure, the patient became headache-free for the first time in several years.

In the literature, patients with hydrocephalus have been shown to respond quite unevenly to atrio-ventricular shunting, but in most instances the descriptions concerned advanced cases with well-established symptoms of dementia, ataxia and incontinence. Our case is reported to stress the importance of early diagnosis and management of hydrocephalus in Paget's disease for the prevention of widespread neurological dysfunction.

RÉSUMÉ: Les auteurs présentent le cas d'un patient de 76 ans souffrant de céphalées sévères de longue date chez qui l'investigation a montré une maladie de Paget associée à une hydrocéphalie. Aucune manifestation neurologique ni musculo-squeletique n'a été en évidence, l'atteinte neuropsychologique était modérée. Un traitement aux disphosphonates n'a amélioré que discrètement les céphalées. Celles-ci étaient tellement importantes qu'un shunt ventriculo-atrial a été effectué. Trois jours après l'intervention, les céphalées ont complètement disparu.

Des cas d'hydrocéphalie dues à la maladie de Paget ont déjà répondu de façon plus ou moins marquée à une dérivation ventriculaire. Toutefois, tous les cas décrits étaient déjà déments, ataxiques et incontinents. Ce cas illustre donc l'importance de faire un diagnostic précoce d'hydrocéphalie chez les patients porteurs d'une maladie de Paget avant que surviennent les complications neurologiques.

Can. J. Neurol. Sci. 1984; 11:69-72

Paget's disease is occasionally responsible for neurological symptoms. These may be secondary to pressure exerted by expanding bone on the brain, brainstem, cranial nerves, spinal cord or nerve roots. Vascular insufficiency may also play a role. Increasing demands by the pathological bone create a state of vascular steal away from neural structures sharing a common blood supply. In malignant degeneration of pagetic bone, there is the additional factor of local invasion and compression of neural elements. Impairment to the flow of cerebrospinal fluid (CSF) may also contribute to symptoms, by bony obstruction of the cisterns in the posterior fossa or by failure of resorption due to disturbances of pacchionian granulations by pagetic bone (Schmidek, 1977).

The dementia associated with Paget's disease has been described by Hann (1901), and communicating hydrocephalus by Riser et al. (1948). Subsequently, several cases of pagetic patients presenting with dementia, ataxic gait and urinary incontinence have been treated surgically by ventriculo-atrial shunt or suboccipital craniotomy with variable results (Culebras et al., 1979; Hens and Van den Bergh, 1979).

We report a 76 year old patient with headaches and communicating hydrocephalus associated with Paget's disease of the skull, who had a favourable evolution following ventriculoatrial shunting.

\section{Case Report}

A 76 year old man was admitted to hospital in February 1982. He had suffered from violent headaches for 35 years. In 1972, he saw a neurologist. At that time the physical examination was normal. An EEG showed some slow activity over the right temporal lobe. On skull $X$-rays, there were subtle pagetic changes in the parieto-occipital area. A diagnosis of migraine was made. Early in the history, the headaches had been intermittent, generalized and unrelated to any trigger factor, but there was throbbing in the head. The episodes would last about 6 hours and recur every fortnight, heralded by nausea. ASA would relieve the headache. The pattern had continued for about 15 years and then, the attacks had started increasing in duration, frequency and intensity.

Three months before admission to hospital the pattern of headaches had changed completely. They had become constant, localized to the occipital area and were accompanied by nausea and vomiting. Straining did not increase the pain and codine offered no relief.

On examination, the patient was a pale, thin man of short stature, complaining of excrutiating headache. He had a prominent forehead and scalp vein distension. The neurological examination was normal; there were no frontal lobe signs nor any disturbance of gait. Hearing was normal. There was no decrease in the range of motion of the neck.

Laboratory tests revealed a hemoglobin of $10.9 \mathrm{~g}$ and several alkaline phosphatase determinations ranged from 216-290 U/l (normal: 22 to 115).

The CSF was clear with a pressure of $150 \mathrm{~mm}$, total protein: $33 \mathrm{mg} \%$, IgG: 2.4 , albumin $20, \mathrm{IgG}$ /albumin: 0.11 , glucose 75 , chloride 120 . No cellular elements were detected.

From the Divisions of Neurology, Neurosurgery and Radiology, Hôtel-Dieu de Montréal and Université de Montréal

Received May 5, 1983. Accepted in revised form November 25, 1983

Reprint requests to: Dr. Chantal Hausser, Department of Neurology, Hôtel-Dieu de Montréal, 3840 St-Urbain, Montréal, Québec, Canada H2W 1T8 
EEG showed non-specific slow activity with some sharp components, over the right centro-temporal area, and less frequency over the left fronto-temporal. Skull X-rays demonstrated Paget's disease mainly in the parietal and occipital bones (fig. 1). A slight degree of basilar impression was also present. The audiogram was normal. The CT-scan showed Paget's changes of the cranial vault and dilatation of cortical sulci (fig. 2). A technicium brain scan showed increased uptake over the vault, but no abnormal intracerebral uptake.

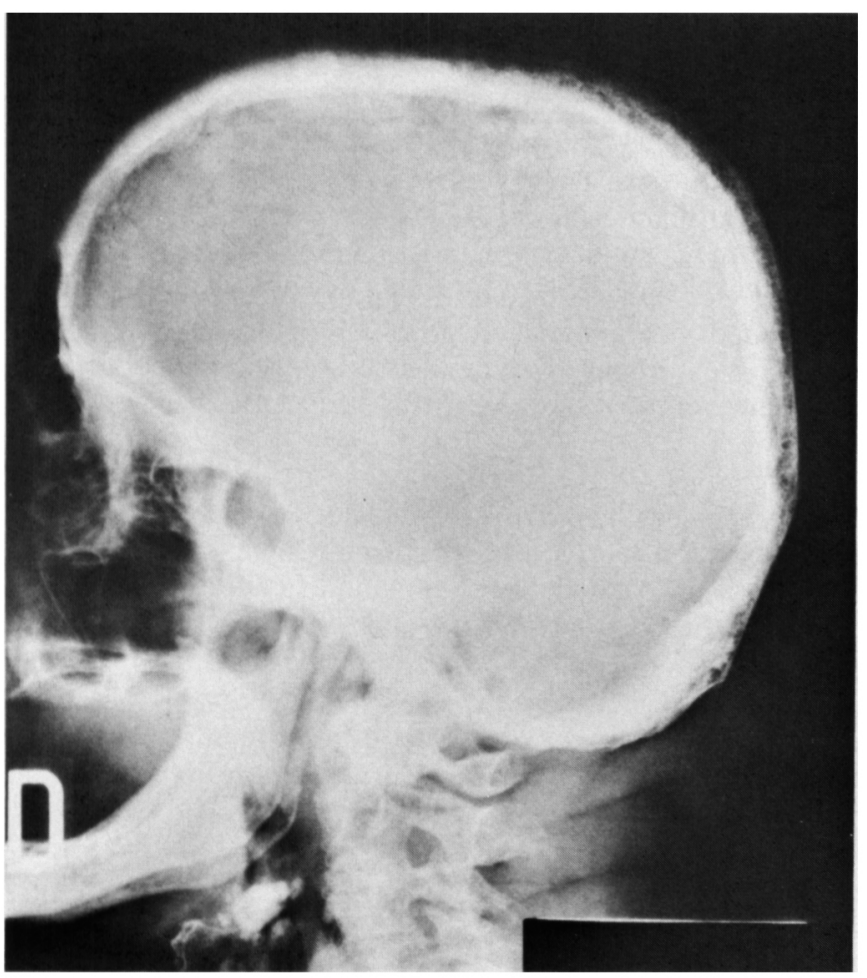

Figure I - Lateral view of the skull. Thickening of the vault with wooly appearance of the parietal and occipital bones suggesting Paget's disease of the bone. Slight basilar impression is seen.

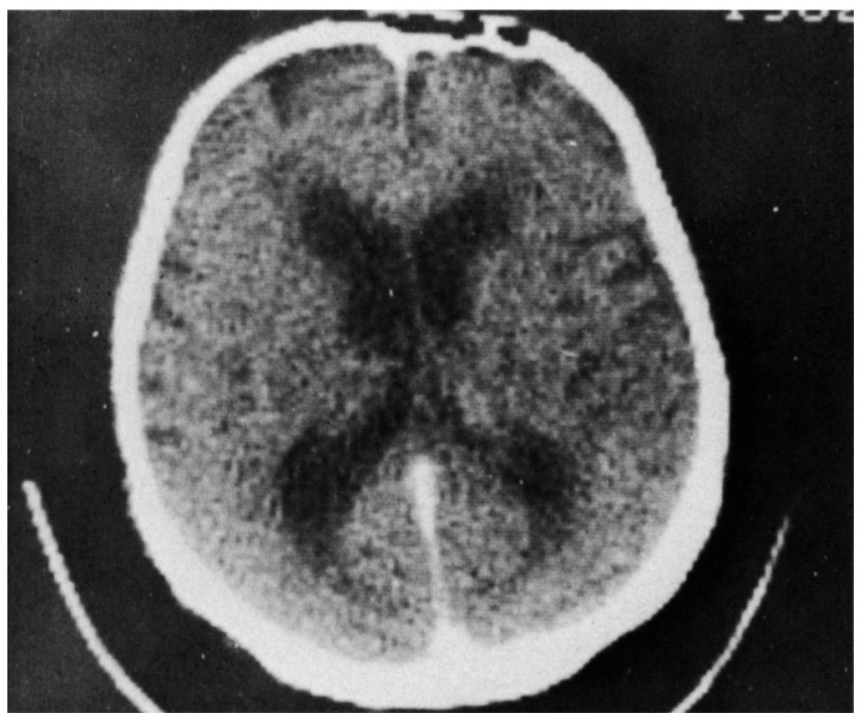

Figure $2-C T$-scan: Dilatation of the lateral ventricles and some degree of cortical atrophy, best shown over the fronto-temporal areas with enlargement of the cortical and inter-hemispheric sulci.
An "'Indium-DTPA isotope cisternogram revealed abnormal flow of CSF with early penetration of the ventricles, but with some stasis in the cisterna magna. More importantly there was poor resorption along the superior longitudinal sinus (fig. 3). The total body ${ }^{32} \mathrm{P}$ bone scan showed increasing uptake only over the skull, consistent with active Paget's disease.

Neuropsychological tests disclosed a visuoperspective and constructive disorganization with constructive apraxia and visuomotor incoordination. There were verbal and visual memory deficits. An overall psychomotor slowing was recorded but intellectual functions were preserved qualitatively: the verbal IQ was 97 and the performance IQ was 84 (table 1A).

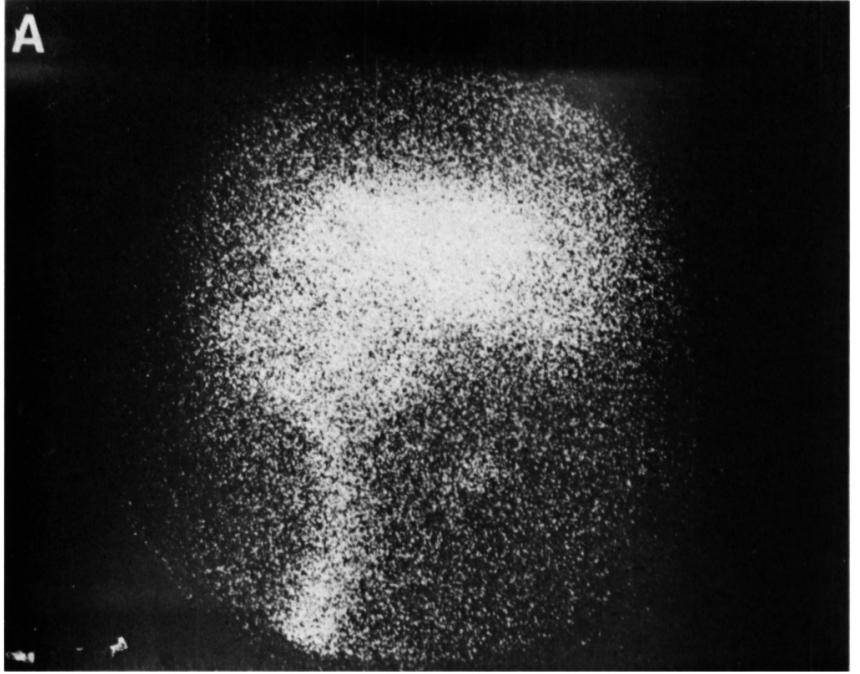

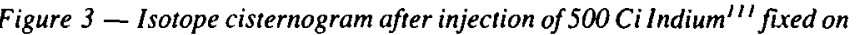
DTPA. Lateral view at $5^{45}$ hours after injection. There is an abnormal and early penetration of the radionuclide in the ventricles. The peripheral circulation is very slow and the CSF is stagnant in the cisterna magna.

Etidronate disodium (Didronal) was given in doses of $300 \mathrm{mg}(5 \mathrm{mg} / \mathrm{kg}$ ) from the first day of admission. A few days later, slight improvement was noted by the patient but he still would call for analgesics regularly. Even Meperidine did not provide any relief. A lumbar tap was done with removal of $250 \mathrm{cc}$ of CSF, without any improvement.

A ventriculo-atrial shunt was established at surgery on March 1, 1982. Pressure in the occipital horn was $80 \mathrm{~mm} \mathrm{H}^{2} \mathrm{O}$. The derivation catheter from the ventricle with a median-pressure Holter valve was connected to a right atrial catheter inserted through the left facial vein. Three days later, the patient was headache-free for the first time in 35 years. His headaches did not recur for 10 months, when he returned to report the recent onset of headaches, similar to what had existed prior to surgery. On examination, it was not possible to depress the Holter valve behind the left ear, and the isotopic flow study confirmed the malfunction. Two days following replacement of the valve, the headaches had again disappeared. Eighteen months following the first shunting operation, the patient is still symptom-free.

Two months after the first operation, neuropsychological tests had shown overall improvement of judgment, abstractive capacity, concentration and mental arithmetic (table 1B). When last seen, 18 months after the initial operation, there was further general improvement of neuropsychological activity and testing (table 1C).

\section{Discussion}

This patient not only complained of headaches, but also had psychomotor retardation, impaired memory and constructive apraxia on psychological tests. His EEG was abnormal; the isotope cisternogram and CT-scan showed hydrocephalus of the communicating type. 
Table 1: Neuropsychological Performance Index

\begin{tabular}{|c|c|c|c|}
\hline & $\begin{array}{c}\text { Before } \\
\text { Shunting }\end{array}$ & $\begin{array}{c}\text { B } \\
2 \text { Months } \\
\text { Following } \\
\text { First } \\
\text { Shunting } \\
\end{array}$ & $\begin{array}{c}\text { C } \\
\text { 18 Months } \\
\text { Following } \\
\text { First } \\
\text { Shunting } \\
\end{array}$ \\
\hline \multicolumn{4}{|l|}{ WAIS } \\
\hline Verbal IQ & 97 & & 101 \\
\hline Performance IQ & 84 & & 89 \\
\hline Global IQ & 90 & & 95 \\
\hline Judgement & 12 & 17 & 17 \\
\hline ARITHMETIC & 3 & 8 & 6 \\
\hline \multicolumn{4}{|l|}{ WECHSLER MEMORY } \\
\hline Memory IQ & 81 & & 104 \\
\hline \multicolumn{4}{|l|}{ ASSOCIATIVE LEARNING } \\
\hline Verbal & 4.2 & 6 & 6 \\
\hline Visual & 7.4 & 5.6 & 8 \\
\hline \multicolumn{4}{|l|}{ FIGURE COMPLEXE } \\
\hline DE REY & 10th pctile & & 20th pctile \\
\hline KOHS BLOCK DESIGN & 11 & 13 & 18 \\
\hline \multicolumn{4}{|l|}{ TAPPING } \\
\hline Right hand & 25 & 28 & 41 \\
\hline Left hand & 27 & 30 & 32 \\
\hline \multicolumn{4}{|l|}{ CRAWFORD DEXTERITY } \\
\hline Total & 29 & 36 & 37 \\
\hline
\end{tabular}

The relationship between the long-standing headaches and the Paget's disease in this patient is at first difficult to establish, since the basilar impression on X-rays was minimal, the CSF pressure was normal and since simple hydrocephalus "ex vacuo" can occur without any direct relationship to coexisting Paget's disease in a 76 year old man. However, headaches are not usually associated with hydrocephalus "ex vacuo". Admittedly, from age 41 to 56 , the headache pattern was typical for migraine, but there was an increase in the severity of the headaches from age 56 into advancing age. This is unusual for migraine.

Finally, in the three months preceding the first admission there was a change in the character of the headaches as they became constant, intolerable and localized to the occiput, in the area where Paget's changes were seen on X-rays. At that point, we thought it was acceptable to correlate the Paget's disease, the hydrocephalus and the headaches.

Neurological complications of Paget's disease are well known but they are rare. The disease itself is rather frequent, and it occurs in $3 \%$ of patients above age 40 (Boudin et al., 1975; Hubault and Bourgeois, 1975; Downey et al., 1980; Schmidek, 1977; Bull et al., 1959). The complications include dysfunction of the spinal cord (paraparesis, paraplegia), brain stem (hemiplegia), eyes (optic atrophy, papillary stasis, proptosis, angioid streaks), cranial nerves (deafness, vertigo, hemifacial spasm, trigeminial neuropathy, hypoglossal palsy, crocodile tears), posterior roots (sciatica) and brain. When the brain is involved, neurological changes (headache, dementia, ataxia, incontinence and drop attacks) may occur, as well as purely mental syndromes (paranoia or manic-depressive psychosis).

Boudin (1975) has proposed a clinical classification of the cerebral complications of Paget's disease: 1) in the latent phase the patient is neurologically normal; 2) in the second phase associated with hydrocephalus, there is psychomotor retardation, impaired memory, ataxia and urinary incontinence; 3 ) in the phase of late decompensation, there are severe neurological manifestations and a rapid evolution with stupor, akinetic mutism and eventually coma. The third phase is not reversible as it relates to vascular compromise due to kinking in the arteriae thalamo-perforantes and choroidae posterior mediales.

Headache is the most frequent neurologic complaint in pagetic patients $(52 \%)$, followed by hearing loss $(46 \%)$. The headaches can be of three types: 1) deep pain in the whole head, constant and unalleviated, in relation to involvement with the vault by Paget's but without involvement of the base of the skull; 2) a sharp localized pain associated with malignant degeneration of Paget's bone; 3) headaches due to the associated hydrocephalus are excerbated by straining and by the recumbent position. With this last type of headache, there is usually a basilar impression on the skull.

Basilar impression is frequently reported in Paget's (Boudin et al., 1975; Taylor and Chakravorty, 1964; Bull et al., 1959) and it appears to be unrelated to the severity of bone involvement by the disease. Mechanical forces acting on softened bone will result in a progressive invagination of the base of the skull and this will impede the flow of CSF through the basilar cisterns, with the production of hydrocephalus.

The basilar impression will also angulate the aqueduct of Sylvius and displace it anteriorly. With further progression of the disease, the displacement of the brain stem will come to occlude the interpeduncular cistern and distort the arteries passing through the perforated substance.

Corrective treatment of the cerebral complications must be initiated before the onset of the phase of decompensation, in order to be effective. On the medical side, disphosphonates (Alexander et al., 1979), Calcitonin (Detilleux et al., 1977) Mitramycin, Actinomycin D, have been tried with mixed results in an attempt to stem the development of the bony lesions of Paget's disease.

The surgical approach has been used in cases of hydrocephalus. Culebras (1974) obtained good improvement in two out of three demented and ataxic patients, following ventriculo-atrial shunting. but the improvement was of short duration. Botez in 1977 reported a 65 year old pagetic female with dementia, parkinsonian features, gait ataxia, grasp reflex of the feet, urinary incontinence and a cerebellar syndrome which improved after shunting. Goldhammer (1979), described a remarkable reversal of dementia, ataxia and incontinence in a 70 year old patient after ventriculoatrial derivation. Hens and Van den Bergh (1977) recorded a good response to ventricular shunt in a patient with hydrocephalusdementia complex.

Our case is the first reported pagetic patient in the literature who had complained of headaches only and who was totally relieved by the ventriculo-atrial shunt. The objective findings represented by the neuropsychologic tests in our patient have also improved since operation.

The interest in this case is the impressive result of the corrective procedure, strongly indicating the importance of an early search 
for hydrocephalus in patients with Paget's disease. Even though experience in the literature to date is anecdotal we propose long-term follow-up of Paget's disease, using neurological and neuropsychological investigations, for an early corrective treatment of deteriorations by shunting, since widespread nervous dysfunction may be irreversible when it has become clinically obvious.

\section{ACKNOWLEDGEMENT}

The authors wish to express appreciation to the Department of Medical Illustration at Hôtel-Dieu de Montréal, to Michelle Fhima for secretarial assistance and to Mireille Oliver for help in the preparation of Table 1 (Neuropsychological tests).

\section{REFERENCES}

Alexandre, C., Trillet, M., Meunier, P., Fisher, C. (1979) Traitement des paraplégies pagétiques par les disphosphonates. Rev. Neurol. 135:8-9, 625-632.

Botez, Mi., Bertand, G., Leveille, J., and Marchand, L. (1977). Parkinsonism-dementia complex, hydrocephalus and Paget's disease. Can. J. of Neurol. Sci. 4:139-142.

Boudin, G., les Besnerais, Y., Goldewski, S., Fabiani, J.M. (1975). Les complications neurologiques des impressions basilaires pagétiques et leur traitement chirurgical. Sem. Hop Paris. 51:145-155.
Bull, J.W.D., Nixon, W.L.D., Pratt, R.T.C., Robinson, P.K. (1959). Paget's disease of the skull and secondary basilar impression. Brain. 82:10-22.

Culebras, A., Feldman, R.G., Fager, C.A. (1974). Hydrocephalus and dementia in Paget's disease of the skull. Journal of Neurol. Sci. 23:307-321.

Detilleux, M., Guillausseau, P.J., Caquet, R., Reynard, M., Metzger, J. (1977). Maladie de Paget avec hydrocéphalie obstructive et état mémentiel. Evolution favorable sous l'effet d'un traitement par la calcitonine. Ann. Med. Intern. 128:8-9, 667-672.

Downey, R. Siris, E.S., Antunes, J.L. (1980. "Crocodile Tears" and Paget's disease: Case report. Neurosurgery. 7:621-622.

Goldhammer, Y., Braham, J., Kosary, I.Z. (1979). Hydrocephalic dementia in Paget's disease of the skull: Treatment by ventriculoatrial shunt. Neurology 29:513-516.

Hann, R.G. (1910). A case of osteitis deformans terminating with cerebral symptoms. Brit. Med. J. 1:135-137.

Hens, L., van den Bergh, R. (1979). Hydrocephalus-dementia-complex in Paget's disease. Clin. Neurol. Neurosurg. 81:4.

Hubault, A., Bourgeois, P. (1975). Les complications neurologiques de la maladie de Paget. Rev. Rhum. 42(10):563-571.

Riser, M., Gayral, G., Lazorthes, G., Hivert, M. (1948). Etat mélancolique grave au cours d'une maladie osseuse de Paget à localisation cranienne exclusive. Ann. Med. Psych. 2:69-76.

Schmidek, H.H. (1977). Neurological and neurosurgical sequelae of Paget's disease of bone. Clin. Orthop. E. Rel. Res. 127:70-77.

Taylor, A.R., Chakravorty, B.C. (1964). Clinical syndromes associated with basilar impression. Arch. Neurol. 10:475-484. 